\title{
Las huellas del miedo en la literatura de viajes medieval: una aproximación metodológica
}

\author{
Traces of fear in medieval travel literature: \\ a methodological approach
}

Pablo Martín Prieto**

\begin{abstract}
RESUMEN
ABSTRACT

El presente trabajo propone una aproximación metodológica al miedo como emoción ligada a los viajes y peregrinaciones en la Edad Media. Una selección de fuentes editadas de la literatura de viajes medieval sirve como

base para el análisis de diversas expresiones de temor debidas a una amplia variedad de viajeros medievales. En estas

fuentes, el mar, los peligros de posibles agresiones, la enfermedad, la soledad y lo desconocido prevalecen ampliamente entre los motivos de temor aducidos por los viajeros. En ellas también se señala la reacción positiva frente al miedo, manifiesta en remedios como la devoción y el conocimiento. El artículo enmarca el interés del tema dentro del ámbito y los métodos de la historia de las emociones.

\author{
PALABRAS CLAVE \\ Miedo, Edad Media, \\ literatura de viajes, emociones.
}

This study presents a methodological approach to fear as a phenomenon connected with travels and pilgrimages in the Middle Ages. A selection of published sources from medieval travel literature is used to analyse expressions of fear on the part of a wide variety of different medieval travellers. The sea, dangers of potential attacks, illness, solitude, and the unknown stand out among the most frequently confessed motives for the fear of travellers in these sources. These sources also record positive reactions to fear as evidenced by solutions found in devotion and knowledge. This study falls within the scope and method of the history of emotions.

\section{KEY WORDS}

Fear, Middle Ages,

Travel literature, Emotions.
\end{abstract}

* Fecha de recepción del artículo: 2011-5-21. Fecha de aceptación del artículo: 2011-1-20.

** Universidad Complutense de Madrid. C.e.: pablomartinprieto@ghis.ucm.es 


\title{
INTRODUCCIÓN CONCEPTUAL: LOS VIAJES Y EL MIEDO
}

Releyendo una de las más sugestivas y olvidadas piezas del conocido ensayista español José Ortega y Gasset, concretamente el estudio que en 1947 dedicó a Leibniz y el arte de la deducción, hallamos una pista interesante sobre la relación antiquísima que, a un nivel tan profundo que toca la misma tectónica donde se fraguan las realidades vecinas del pensamiento y el lenguaje, se reconoce entre los conceptos de «viaje» y «peligro» y sus campos semánticos asociados. Dice, así, Ortega:

\begin{abstract}
«Experiencia, empeiría - $\varepsilon \mu \pi \varepsilon ı 1 \alpha-$, es una palabra que en griego, como en latín, vive de la raíz per. [...] En las lenguas germánicas existe igualmente per en la forma de fahr. Por eso, experiencia se dice "Er-fahnung". Esta raíz pertenece a un "campo verbal" y a un "campo pragmático" correspondiente sumamente curiosos. Existe en armenio y en sánscrito. Es, pues, una vetustísima palabra indoeuropea que expresa una vetustísima vivencia. [...] La nueva idea, que va a esclarecernos toda la serie, es que en per se trata originariamente de viaje, de caminar por el mundo cuando no había caminos, sino que todo viaje era más o menos desconocido y peligroso. [...] En los viajes, a la vez se arrostran "peligros" de los cuales hay que buscar salidas, portus y euporías. En los viajes se ven muchas cosas. Por eso los árabes llaman a sus libros de viajes "libros de andar y ver". El empirismo o experiencia es, pues, un efectivo "andar y ver" como método, un pensar con los pies [...]»1.
\end{abstract}

En efecto, la antigua raíz indoeuropea per vive (pervive) en numerosas palabras latinas relacionadas con un campo semántico al que pertenecen la experiencia como itinerario, y el viaje como peligro. Experimentum, experientia, empirismo, nos recuerda Ortega. Y antes aún, peregrinar. el viaje del peregrino, que siempre es por definición un extraño, es la peregrinatio o también la perambulatio; el adverbio latino peregre describe la vivencia de estar «en el extranjero», esto es, vivir como vive el peregrino; gana en conocimiento, en peritia, el que por viajar ha visto muchas cosas y ahora es experto en ellas, perito. En latín, perire es marcharse hasta el final, definitivamente, esto es, morir, que en el fondo no es sino emprender «el último viaje». Y ya que jugamos con las palabras, no estará de más recordar en el frontispicio de este trabajo nuestro que viajar, peregrinare, nunca queda lejos del peligro, periculum, como también sabemos que el viajar, en inglés to travel, con frecuencia exige arrostrar incomodidades, trabajos: troubles, travails ${ }^{2}$.

Viaje y peligro, viaje y trabajos: tal parece que esta doble pareja de conceptos relacionados no puede pasar inadvertida a quien estudia el miedo: pues, precisamente, el peligro y los trabajos se cuentan entre las vivencias traumáticas o desa-

1 ORTEGA Y GASSET, J., «La idea de principio en Leibniz y la evolución de la teoría deductiva», en sus Obras completas, t. VIII, Madrid, 1962, pp. 59-356 [174, 176, 177].

2 Naturalmente - como no ignoraba Ortega-, la serie indoeuropea completa de asociaciones entre viaje o experiencia y peligro se conserva admirablemente en el horizonte lingüístico germánico: en alemán actual la raíz fahr da vida a palabras como fahren (viajar), Erfahrung (experiencia), erfahren (experimentar), Gefahr (peligro), gefährlich (peligroso), etc. 
gradables que, en todo tiempo y lugar, han despertado el miedo en los hombres, como también ha espoleado su inventiva y su afán de superación el deseo de superar a uno y otros. Sentir miedo ante los peligros y ante las dificultades, los trabajos: es algo inmediato, que desde cualquier aproximación antropológica no precisa de largas aclaraciones; y si en el viajar se hallan agazapados el peligro y los trabajos, la asociación entre viaje y miedo queda clara en el fondo de aquella mentalidad antigua que aún se expresa y vive en el acervo común de nuestra tradición indoeuropea.

Naturalmente, la relación entre los viajes y el miedo no llega a ser por entero previsible, ni configura un esquema especular de uno a uno entre cada lance de peligro en un viaje y una experiencia de temor asociada (lo que, en términos matemáticos, llamaríamos una biyección o correspondencia biunívoca): en efecto, tantas veces se observa que, bien por inconsciencia, temeridad, indiferencia o simple frialdad de carácter, los peligros ciertos y comprobados de un viaje no despiertan el miedo que cabría esperar en quienes los arrostran, o que, en otras tantas ocasiones, el miedo, como sensación subjetiva y personalísima, asalta al viajero sin que medie motivo claro de peligro aparente. En el cuerpo de nuestro estudio, dedicados a recoger y analizar diversos ejemplos de experiencias de temor referidas a los azares de viajes arriesgados - como en alguna medida lo eran todos durante los siglos medievales - , podríamos multiplicar sin dificultad los casos de temores que a nuestros ojos parecen excesivos o infundados, y también podemos anotar la buena presencia de ánimo, o la sequedad expresiva, de viajeros de aquellos tiempos que atravesaron por experiencias traumáticas de gran riesgo objetivo sin llegar a referir sentimientos de temor.

Tocamos acaso, en este último punto, un aspecto esencial del fenómeno: como vivencia subjetiva, el miedo es en última ratio inseparable de los mismos términos en que lo sienten y expresan quienes lo padecen. Un cronista seco e inexpresivo puede silenciar como irrelevantes los sentimientos asociados a un viaje, y de esta manera el miedo realmente sentido ante sus riesgos y azares, nunca reflejado en el residuo escrito de la aventura, queda escondido en los términos de su relato, sin que al historiador actual le quepa alcanzar un conocimiento claro y no conjetural del mismo. En otras ocasiones, el miedo que el viajero ha sentido se disimula en la cuenta escrita que da de su viaje, pero no tanto que impida entreverlo como al trasluz de sus reacciones ante los acontecimientos que relata: entra aquí en juego la finura del lector para detectar esos indicios casi invisibles de una emoción que, a pesar de las precauciones del narrador de época medieval, tiñe todavía esos pasajes. El carácter personal diverso de los distintos narradores y cronistas de viajes, y la índole misma de sus relatos, con las inevitables diferencias de propósito, estilo y talento literario patentes en los distintos textos, condicionan así pues nuestra capacidad de aproximación a una realidad mental, un fenómeno del imaginario, elusivo y en buena medida inaprensible: el miedo, lo sabemos, ha debido ser y ha sido un compañero constante de peregrinos y viajeros a lo largo de toda la Edad Media, y la mayor o menor expresividad de las fuentes de la época a la hora de reflejarlo no nos vela su omnipresencia. 
En las siguientes páginas pasaremos revista a una cierta cantidad de testimonios de viajeros medievales, escogidos sin otro método que el de procurar dibujar un panorama amplio, variado y representativo de las modalidades y experiencias de viaje más frecuentemente relatadas en aquellos tiempos. Cedemos la palabra a los propios protagonistas de aquellos viajes, a quienes los narraron para utilidad y beneficio de sus contemporáneos o por el simple placer de referir a otros su propia experiencia. Dejando a un lado las convenciones de estilo que, en su conjunto, van confirmando y recreando los arquetipos de la literatura de viaje como un género en sí mismo, los rasgos de observación personal y los detalles de espontaneidad de muchos de estos narradores de viajes medievales traslucen una impresión de viveza que difícilmente sobrevive a una explicación o a una paráfrasis de lo que ellos mismos dictaron o escribieron. Por ello, estimamos muy útil a nuestro propósito conocer y reproducir los términos textuales en que aquellos narradores consignaron, más o menos de grado, de manera más o menos natural o convencional, su vivencia del miedo a lo largo de sus viajes.

\section{LA EDAD MEDIA, ÉPOCA DE VIAJES..., Y DE PELIGROS}

Son muchos los fenómenos que a gran y a pequeña escala permiten caracterizar la Edad Media como una época de gran movilidad humana: desde las migraciones de pueblos enteros que acompañaron la misma gestación del periodo, hasta los grandes viajes de descubrimiento que se despliegan en sus últimos siglos, pasando por las manifestaciones de casi nomadismo que se descubren afectando a la vida cotidiana de los diversos estratos sociales (las cortes itinerantes de los monarcas, altos funcionarios religiosos y seculares desempeñando misiones políticas y diplomáticas, caballeros de fortuna, misioneros evangelizadores, clerici vaganti, campesinos que marchan a vivir a la ciudad, vagabundos, entre muchos otros ejemplos ${ }^{3}$ ), sin olvidar movimientos expansivos y colonizadores (como el Drang nach Osten germánico, la Reconquista hispana, las mismas cruzadas de Tierra Santa) o la realidad tan especial de las peregrinaciones, los viajes por causa de piedad (a veces también por sed de aventura) que ponen en camino a personas de toda condición en pos de los santuarios mayores y menores de la Cristiandad.

La bibliografía especializada acerca de estos fenómenos de movilidad en los tiempos medievales es tan copiosa y variada, que resultaría temerario pretender evocar aquí siquiera una selección de la misma. El tema de los viajes, siendo tan rico, admite muy diversas formas de aproximación; en el mismo panorama de la literatura medieval, tanto en lengua latina como en las diferentes lenguas vernáculas, ofrece un cauce generoso para el estudio de los viajes desde varias perspectivas, con textos tan conocidos como los extraños viajes simbólicos de san Brandán y sus compañeros de navigatio, el periplo irrepetible de la Commedia del Dante, o el mundo mucho más fa-

${ }^{3}$ F. CARDINI hace referencia al casi nomadismo de las sociedades europeas antes del siglo XIII: Dal Medioevo alla medievistica, Génova, 1989, cap. 5. 
miliar de los peregrinos que se encuentran en el camino de Canterbury y, para aliviar el tedio de la ruta se narran unos a otros los sabrosos cuentos recogidos por Chaucer.

A medio camino entre la literatura y la historia, la figura del homo viator, de los homines in via, de los peregrinos que en la Edad Media, desafiando el peligro se hacían al camino, y por un tiempo cambiaban de vida escapando a las coordinadas de su anterior cotidianidad, ha sido objeto de una atención particular, por cuanto en ese desclasamiento temporal que comporta su viaje, en ese aflojamiento de los lazos que habitualmente determinan las relaciones de identidad y pertenencia en la vida previa que aquellos hombres y mujeres dejaban atrás cuando comenzaban su peregrinación, el estudioso halla la ocasión de conocer a aquellas gentes en un momento especial y diferente de sus vidas. Describiendo la realidad de estos peregrinos, P. A. Sigal emplea la expresión «exilio voluntario» del medio familiar y social, y también la de «marginación temporal», como si al comenzar su aventura los peregrinos abrieran un verdadero paréntesis en sus vidas ${ }^{4}$; R. Oursel se ha referido convincentemente a la «soledad del peregrino románico" ${ }^{5}$ : este es el elemento negativo, se refiere a la familiaridad y la solidaridad que el peregrino pierde o deja atrás cuando se hace al camino ${ }^{6}$; pero (es la otra cara de la medalla) quien inicia una peregrinación halla a otros semejantes en su camino, entra en un nuevo colectivo social con sus propias normas de vida, su propia solidaridad, su propia auto-representación o autoconciencia grupal. Esta nueva solidaridad que une a los hombres del camino responde a una necesidad objetiva de ayuda mutua y de defensa colectiva frente a los peligros que a cada paso acucian a los peregrinos y viajeros.

$Y$ he aquí que encontramos nuevamente la antiquísima asociación entre viaje y peligro (travel/trouble). «Los peregrinos y otros homines in via constituyen, por su misma condición de desplazados/desclasados, un colectivo especialmente vulnerable a violencias, abusos y conflictos de todo tipo, pues mientras dura su viaje se hallan temporalmente privados de la protección que a los hombres medievales proporcionaba la red de las relaciones que mantenían con su entorno vital inmediato ${ }^{7}$. Sería largo recapitular las diversas ocasiones de peligro que los viajeros medievales encontraban en el camino: la ocasión de extraviarse, el hambre, la sed, los naufragios, las inclemencias del tiempo, el asalto y el robo, las agresiones de otros hombres y de animales, los engaños y extorsiones, las intoxicaciones y envenenamientos, las lesiones, las enfermedades congénitas o contagiosas...8

4 SIGAL, P. A., Les marcheurs de Dieu. Pèlerinages et pèlerins au Moyen Âge, París, 1974.

5 OURSEL, R., Caminantes y caminos. Las rutas hacia Santiago de Compostela, Madrid, 1985, parte 2, cap. 9.

6 «Peregrinar, del latín peregrinare, que a su vez procede de per ager, o sea a través del campo y por extensión a través de los países, es caminar a través del mundo, pero fuera del mundo»: RIQUER, I. de, «Ad modum peregrinorum», en Miscel.lània en homenatge al P. Agustí Altisent, Tarragona, 1991, pp. 245-265 [246].

7 MARTÍN PRIETO, P., «Lugares de hospedaje: un espacio de conflicto en la Castilla medieval», Cuadernos de Investigación Histórica, 23 (2006), pp. 305-325 [306].

8 ARRANZ GUZMÁN, A., "Los peligros del Camino de Santiago», en Actas del Congresso Internacional dos caminhos portugueses de Santiago de Compostela, Lisboa, 1992, pp. 135-151. 
pero, como hemos advertido en nuestra introducción, resultaría demasiado mecánico y demasiado sencillo establecer una mera correspondencia entre ocasiones de peligro y vivencias de miedo. Nuestro objetivo es aproximarnos al miedo que sentían los viajeros, y, concretamente, al residuo escrito que esta emoción puede haber dejado en la cuenta de sus viajes que ellos mismos relataron, dictaron o escribieron. El miedo de aquellos viajeros, en la medida en que podemos conocerlo, no se corresponde siempre con lo que desde nuestra mentalidad actual cabríamos esperar que hubieran temido, o, por mejor decir, nos representamos que nosotros mismos habríamos temido hallándonos en su lugar. Como tendremos ocasión de apreciar, si bien la naturaleza humana es en todo tiempo y lugar una y la misma, y debido a esto las experiencias de temor que aquellos viajeros refirieron son, en su mayor parte, extrapolables, también existen casos de notoria omisión de cualquier expresión de temor ante peligros objetivos, y también, especialmente, remedios que aquellos hombres empleaban para hacerle frente al miedo a los que la mentalidad actual dominante no atribuye la misma virtud tranquilizadora (singularmente, la oración).

En términos generales, si pensamos en los peligros que afrontaban los viajeros medievales, podríamos distinguir varios tipos generales: por un lado, peligros debidos a la aspereza o pobreza del país que atravesaban (hambre, sed, calor, frío); por otro, los que cabía esperar de las fieras o de los hombres que hallaran en su camino (asaltos, robos); por último, un peligro especial amenaza, si no la integridad física de los viajeros, sí su integridad moral: el pecado constituye también un peligro que tener en cuenta, pues en muchos casos los lances del camino ofrecen al viajero ocasión propicia para pecar.

Naturalmente, es relativamente sencillo hallar referencias a todos estos tipos de peligros en las fuentes de la época. Por ejemplo, numerosos privilegios reales castellanos aluden a los peligros físicos que acuciaban a los viajeros: «las grandes fortunas e niebes del ynbierno», «muchos robos e males e dannos e muertes de omes» que acaecen en el camino, pasos donde «es camino muy seco para el tienpo de verano que non ay agua en el», «que por estar asy muy yermo e despoblado se recresçian muchos trabajos e danno a los recueros e otras personas caminantes, padesçiendo mucha fanbre e sed por non fallar en el camino vino nin agua nin viandas para comer e bever», «por quanto la dicha tierra es fragosa e esta despoblada e se suelen por alli fazer saltos e robos e otros males e dannos», a cargo de «omes robadores e malos que roban a los que por ally van e pasan»: la relación de referencias similares podría alargarse sin dificultad ${ }^{9}$.

En cuanto a los peligros para el alma, podrían citarse diversos textos procedentes de las compilaciones sinodales de las diócesis hispanas bajomedievales.

\footnotetext{
9 Archivo General de Simancas, M. P., legajo 3, fols. 7 y 80; legajo 4, fol. 154; Archivo Histórico Diocesano de Palencia, Dueñas, carpeta 196: cit. en REGLERO DE LA FUENTE, C. M., «Viajeros, poblamiento y fiscalidad en la Castilla del siglo XV», en Viajes y viajeros en la España medieval. V Curso de Cultura Medieval, Aguilar de Campoo 1993, Madrid, 1997, pp. 361-374 [363].
} 
Los clérigos, se nos informa, para no exponerse al pecado y no causar escándalo, deberían abstenerse de frecuentar las tabernas, pero les estaba permitido entrar en ellas cuando viajaban y lo largo del camino no les dejaba otro remedio que visitarlas:

«Visitando en nuestro obispado [Burgos], nos ha sido denunciado que algunos clerigos que, pospuesto el temor de Dios, en mal ejemplo de los que los ven, frecuentan las tavernas e comen e beven e juegan en ellas, e que otros se dan tanto al vino que se embriagan e toman dello, de lo qual se han causado muchos males. Por ende, establecemos e ordenamos e mandamos que de aqui adelante ningun clerigo de orden sacra deste nuestro obispado coma ni beva ni juegue con ninguno en la taverna en ningun tiempo, salvo si fuere camino de un lugar a otro, que en tal caso permitimos que pueda comer e bever en ella, con tanto que no este largo espacio ni tardança» ${ }^{10}$.

Otra ocasión de pecado para los clérigos viajeros surgía cuando hallaban y acompañaban a mujeres en su camino:

«E porque somos informados que algunos clerigos, no mirando su honestidad, acompañan dueñas y doncellas, e, asimismo, las llevan a las ancas de las mulas, lo qual es todo contra la honestidad de la clerezia» ${ }^{11}$.

Las mismas romerías, peregrinaciones y procesiones ofrecían ocasión de pecado, no sólo a los clérigos, sino también a los laicos:

«[...] hemos sido muchas vezes informado, e por experiencia lo hemos visto e es publico e notorio en muchas villas e logares deste nuestro obispado [Burgos], de los daños e inconvenientes que se han seguido e siguen en los tiempos de las rogaciones e ledanias e otras procesiones que los pueblos suelen hazer por sus devociones, quando salen de los terminos de sus propios logares e van a otras iglesias de algunas villas e logares o monasterios donde tienen devocion, e concurren en ellas diversos pueblos en un tiempo, sobre sus pundonores e preeminencias que unos pretenden tener sobre otros, han acontescido muertes e escandalos e ruydos muy travados e muchas personas heridas; e, asimismo, sin oyr missa e los otros oficios divinos, comen e beven por los caminos excesivamente, e hazen bayles e danças e otros actos profanos e deshonestos, de que nuestro Señor es muy deservido $[\ldots]{ }^{12}$.

En todos estos sentidos se podría afirmar que, de acuerdo con la mentalidad de la época, los viajes eran peligrosos, y no sólo para el cuerpo, sino también para el alma, de los viajeros.

10 Diócesis de Burgos, compilación sinodal de 1503-1511: Synodicon Hispanum. VII Burgos y Palencia (GARCÍA GARCÍA, A., ed.), Madrid, 1997, § 354, p. 247.

11 Compilación sinodal de Burgos, 1503-1511, ibidem, § 323, p. 231.

12 Sínodo de Burgos, 1511, ibidem, § 23, p. 294. 


\section{OPINIONES GENERALES SOBRE LOS VIAJES Y SUS AZARES EN LA ÉPOCA}

Podemos considerar, en primer lugar, algunos testimonios de la época que vienen a expresar la opinión, al parecer muy extendida, de que viajar constituía entonces un negocio arriesgado, o cuando menos, delicado. La identificación del viaje y del peligro parecía clara y constante en la mente de aquellas gentes, por razones bien comprensibles.

Una opinión lapidaria, reforzada por su expresión en forma tripartita y por el prestigio de su autor, nos la transmite un escritor anónimo de finales del siglo XV, cuando refiere que Eberhard el Barbudo, conde de Württenberg, luego de peregrinar a los Santos Lugares, afirmó:

«Hay tres cosas que nadie puede aconsejar ni desaconsejar: el matrimonio, la guerra y el viaje a Tierra Santa, porque pueden empezar bien y acabar mal»13.

Resulta interesante el punto de vista, y especialmente la manera como mete en el mismo saco, el saco del peligro asociado a la incertidumbre, tres aventuras que considera siempre de resultado imprevisible, entre las cuales, por propia experiencia, debía figurar la experiencia de la peregrinación.

Los peligros de emprender una peregrinación estaban claros en la mente de las gentes del Medievo; muchos peregrinos lo eran por expiación y conciencia de culpa por sus pecados, por haber realizado un voto o promesa en ocasión de una grave dificultad, o en cumplimiento de un castigo o penitencia canónica ${ }^{14}$. En algunos casos, el miedo espoleaba al peregrino: el miedo a quebrantar el voto o promesa de emprender la peregrinación hecho anteriormente se recuerda a menudo de manera expresa en relatos piadosos acerca de los milagros de castigo fulminados por los santos titulares de cada santuario destinatario de la peregrinación sobre aquellos que se comprometieron a visitarlos y, más tarde, olvidaron o retrasaron el cumplimiento de aquella promesa ${ }^{15}$. Para muchos, pues, la peregrinación no era una ocasión gozosa, ni siempre el resultado de una elección voluntaria. En la mente de aquellas gentes, se presuponía que cada peregrino arrastraba una historia obscura o de penalidad que explicaba el motivo de su peregrinación. Esta noción y esta certeza de que peregrinar es tan penoso y peligroso que no se emprende porque sí, con ligereza de ánimo o simplemente por placer, está tan extendida en la época, que aparece reflejada en los textos literarios más diversos, como por ejemplo en el famoso Roman de Renard, uno de cuyos episodios autó-

${ }^{13}$ Citado en SURDEL, A.-J., «Oultremer. La Terre Sainte et l'Orient vus par des pèlerins du XVe siècle", en Images et signes de l'orient dans l'Occident médiéval, Aix-en-Provence, 1982, p. 331.

14 Sobre el peregrinaje penitencial, cfr. SUMPTION, J., Pilgrimage: An Image of Mediaeval Religion, Londres, 1974, pp. 98-113.

15 Así, por ejemplo, en el caso de los milagros con los que santo Tomás de Canterbury castigaba a quienes deshonraban la promesa que antes habían hecho de visitar su santuario: cfr. WARD, B., Miracles and the Medieval Mind, Aldershot, 1987 (2ª ed.), pp. 93-94. 
nomos más elaborados es el Pèlerinage de Renard, que abarca casi quinientos versos. En este relato de ficción, Renard, un zorro humanizado, se confiesa con un ermitaño, pero sus pecados son tan graves, que éste no se atreve a darle la absolución y lo remite a Roma, a donde marcha en peregrinación; por el camino se le unirán algunos compañeros: Belin el cordero y Bernard el asno. Precisamente, cuando Renard y Belin hallan a este último, el asno, curioso sobre ese viaje que comparten un zorro y un cordero, les hace una pregunta muy significativa, que por sí sola viene a ilustrar cuanto tenemos dicho sobre el tema:

«¿Qué desgracia os ha sucedido para que tú y el señor Belin os hayáis hecho peregrinos?»16.

Ciertamente, una peregrinación no era algo para emprender a la ligera. $Y$ aunque en ella hubiera, en el mejor de los casos, motivos para reconfortarse con la camaradería de otros peregrinos, lo cierto es que la experiencia, en términos generales, era áspera y arriesgada. Como resume el autor del famoso Códice Calixtino, pieza literaria central de la gran peregrinación a Santiago de Compostela:

«El camino de la peregrinación es cosa muy buena, pero es estrecho. Pues es estrecho el camino que conduce al hombre a la Vida» ${ }^{17}$.

Numerosos son los testimonios que aluden, directamente o de pasada, a las dificultades del peregrino, y al miedo en que vive durante su aventura. Así, el dominico alemán fray Félix Fabri, que a finales del siglo XV dejó escrito el relato, muy interesante y expresivo, de sus dos viajes a Tierra Santa, realizados en 1480 y $1483^{18}$, cuando se entretiene en describir, con trazos muy vivos y un penetrante sentido de la observación, el aspecto y el equipamiento de los peregrinos, menciona un detalle sintomático: la larga barba que éstos lucirán

«en una cara cerosa y pálida debido a los trabajos y peligros» ${ }^{19}$.

La palidez del miedo, sin duda.

\section{LOS MIEDOS DEL CAMINO}

Entrando a ilustrar más por menudo, con una serie de ejemplos tomados de fuentes de la literatura de viajes de la época, las experiencias de temor que asal-

16 Roman de Renard (ROQUES, M., ed.), París, 1955, versos 9036-9038.

17 Liber Sancti Jacobi, Codex Calixtinus (MORALEJO, A., et alii, eds.), t. I, Santiago de Compostela, 1951, p. 204.

18 Fratris Felicis Fabri Evagatorium in Terrae Sanctae (HASSLER C. D., ed.), 3 vols., Stuttgart, 1843-1849.

${ }_{19}$ Citado en GUGLIELMI, N., Guía para viajeros medievales (Oriente. Siglos XIII-XV), Buenos Aires, 1994, p. 129. 
taban a los viajeros medievales, podemos desde luego elaborar una simple clasificación de dichas vivencias de acuerdo con el motivo que en cada caso excitaba el miedo.

\subsection{El miedo a la agresión}

La inseguridad - cualidad que en relación con los caminos podía considerarse crónica en los tiempos medievales, como sin duda lo fue en toda Europa al menos hasta el final del Antiguo Régimen - hace razonable temer las asechanzas de los asaltantes y bandidos que podían caer de improviso sobre los viajeros; pero quienes se hacían al camino debían contar también con el peligro de las soldadescas, así como con la posible hostilidad de los extranjeros, especialmente en tiempo de guerra.

Debido a estos peligros, la soledad engendraba temor en los viajeros, que buscaban asociarse a otros compañeros o disponer, cuando ello era posible, de escolta, para arrostrar con garantías la amenaza de los largos itinerarios o de los tramos con mala reputación. Así, cuando el mentado dominico fray Félix Fabri emprendió la travesía de los Alpes, en abril de 1493, en el curso de su segunda peregrinación a Tierra Santa, solicitó al conde de Kirchberg que le facilitara un acompañante para la travesía, pues, en sus propias palabras,

«ese tramo es bastante inseguro y yo temía cabalgar solo [...] recuerdo con cuántas angustias transité por ese camino en mi primera peregrinación» ${ }^{20}$.

Sin duda, este recelo a cuenta de la inseguridad de los caminos, aun inconcreto, se refería a la eventualidad de sufrir una agresión, un asalto. El miedo a los bandidos acompañaba frecuentemente a los viajeros medievales. Es el caso del barón León de Rosmithal y sus acompañantes cuando entre 1465 y 1467 visitan España; de acuerdo con la relación de este viaje debida a Tetzel, un miembro del séquito del barón, la experiencia de vivir siempre entre extranjeros les causaba una permanente tensión e inseguridad; su testimonio enfatiza con especial insistencia el miedo que sintieron al atravesar una Cataluña en guerra:

«Sufrimos mucho viviendo siempre inseguros [...]. Pasamos entonces [en Cataluña] entre los mayores ladrones y malvados y atravesamos un país pobre y árido sin seguridad alguna para nuestras vidas y siempre llenos de sobresaltos, porque querían matarnos a todos y robarnos» ${ }^{21}$.

El mismo recelo estuvo presente cuando, procedentes de Portugal, entraron en Castilla, país en guerra donde, por haber sido recibidos anteriormente por Enrique

20 HASSLER, Evagatorium, t. I, pp. 68 y 71.

${ }^{21}$ GARCÍA MERCADAL, J. (ed.), Viajes de extranjeros por España y Portugal, t. I, Salamanca, 1999, p. 284. 
IV, no podían esperar hospitalidad en los lugares que estaban por el llamado «Alfonso XII»:

«Después de visitar al rey de Portugal, cabalgó mi señor hacia Castilla, y hubimos de atravesar una región cuyos habitantes eran partidarios del rey nuevo, en donde ardía la guerra y robaban a la gente. Vímonos, pues, obligados a caminar sin descanso, siempre inquietos y recelosos, y no quisieron dejarnos penetrar en ninguna de las ciudades partidarias del joven rey»22.

La legislación cuidaba de reprimir en lo posible las actividades delictivas que tomaban por víctimas a quienes frecuentaban las grandes rutas de peregrinación, como el Camino de Santiago. No sólo algunos maleantes se hacían pasar por peregrinos para aprovecharse del hospedaje y la ayuda que se dispensaba a los verdaderos, sino que incluso estos falsos peregrinos se unían a los grupos de los auténticos para robarles cuando hallaban la ocasión de hacerlo ${ }^{23}$. El miedo se introducía, pues, hasta los mismos albergues, fondas, hosterías y otros lugares de alojamiento, donde los viajeros eran muchas veces objeto de engaños, malos tratos, robos y violencias, circunstancia ésta que ha sido reflejada ampliamente en toda una literatura que tiene en el célebre sermón Veneranda dies uno de sus primeros y más expresivos ejemplos ${ }^{24}$. Un ejemplo particularmente grave y espectacular, por la alta personalidad a quien afectó, nos sirve de ilustración de este detalle: de cómo el peligro y el miedo podían introducirse hasta los mismos alojamientos de los viajeros, de quienes se hallaban desplazados de sus lugares habituales de residencia. Leemos en la Historia Compostellana que Gudesteo, antecesor de Gelmírez en la sede de Santiago, fue a pasar la cuaresma a Iria y se alojó en una casa (probablemente la de los canónigos) junto a la iglesia de la localidad, pero por la noche fue víctima del asalto de ciertos hombres armados:

«En el silencio de una intempestiva noche, penetrando una perversísima cuadrilla de traidores en el dormitorio ante las paredes de la iglesia, donde junto a los canónigos daba descanso a sus miembros —oh, dolor- despedazaron al obispo» 25 .

Por lo que se refiere a los soldados, enemigos y extranjeros en tiempo de guerra, son muchos y muy variados los testimonios del miedo que inspiraban a los viajeros. En cierta ocasión, uno de los compañeros del barón de Rosmithal, a cuyo viaje de 1465-1467 por tierras españolas ya hemos hecho referencia, derrotó en la lucha a un lugareño, y más tarde, cuando los forasteros se habían retirado a su posada, una banda armada cercó la casa con actitud hostil, probablemente en

22 GARCÍA MERCADAL, Viajes, t. I, p. 281.

23 «fueron perseguidos los bandidos y vagabundos que se aprovechaban de las limosnas, de los privilegios y de las hospederías sólo para auténticos peregrinos, y los ladrones que se unían a los grupos para robarles. De éstos procede el término francés coquillard, por la concha o coquille de los peregrinos jacobeos»: RIQUER, «Ad modum peregrinorum», p. 250.

24 MARTÍN PRIETO, «Lugares de hospedaje», passim.

25 Historia Compostellana (SUÁREZ, M., CAMPELO, J., eds.), Santiago de Compostela, 1950, p. 338. 
son de venganza. Reuniendo a sus hombres para hacer frente al ataque, el barón de Rosmithal los arengó para que se aprestaran con ánimo a defenderse, pero no pudo ocultar en su discurso el miedo que le inspiraba la comprometida situación:

«Ánimo, pues, y resistámosles como cumple a buenos y fuertes varones hasta donde nos alcancen las fuerzas; yo, aunque tengo el mismo temor por el éxito que cualquiera, no me apartaré de vosotros, vivos o muertos ${ }^{26}$.

El franciscano fray Giovanni del Pian del Carpine relata en su Historia Mongolorum la misión que lo condujo, a él y a sus compañeros, al khan de Mongolia, atravesando durante su viaje, entre 1246 y 1247, países exóticos donde recordaba muy bien, entre otros peligros, el de ser agredidos por los extranjeros:

«a pesar de que temiéramos ser asesinados por los tártaros o por individuos de otras naciones o ser sometidos a un perpetuo cautiverio o ser afectados más allá de nuestras fuerzas por el hambre, la sed, el calor, los ultrajes y las fatigas, cosas éstas que nos ocurrieron mucho más de lo que creíamos, exceptuando la muerte y el cautiverio perpetuo ${ }^{27}$.

Los ultrajes, decía este franciscano: y muchas veces, de los extranjeros los peregrinos no sólo debían temer los robos o las agresiones, sino también las humillaciones y vejaciones que les causaban: estos malos tratos vejatorios menudeaban especialmente en Tierra Santa, en los lugares in partibus infidelium, donde muchos musulmanes anónimos disfrutaban maltratando a los peregrinos. El recuerdo de estos malos tratos degradantes es consistentemente evocado por la mayoría de los viajeros que recorrieron los santos lugares cuando éstos ya no estaban en manos cristianas; así, por ejemplo, tenemos el testimonio al respecto del florentino Giorgio Gucci, que en 1384 peregrinó a Tierra Santa y describe elocuentemente las zancadillas, insultos, blasfemias, tirones de capucha, ataques a las cabalgaduras, bofetadas, lanzamiento de polvo a los ojos, de agua desde las ventanas, apedreamiento, golpes con cañas, con el puño, etc., de que por costumbre eran objeto los peregrinos occidentales ${ }^{28}$.

En 1294, el dominico fray Riccoldo da Monte di Cruce y sus compañeros peregrinaron a Tierra Santa, donde giraron la habitual visita a los santos lugares; cuando en la relación de su viaje este fraile describe la entrada a la sala del Cenáculo, indica que todos Iloraban de emoción, pero también, se permite aclarar, por miedo de la hostilidad de los musulmanes que rodeaban el lugar: «e temendo fortemente di esser morti dai sarracini» 29 .

26 GARCÍA MERCADAL, Viajes, t. I, p. 273.

27 T'SERSTEVENS, A. (ed.), Los precursores de Marco Polo, Barcelona, 1965, p. 159.

28 Visit to the Holy Places of Egypt, Sinaï, Palestine and Syria in 1384, by Frescobaldi, Gucci and Sigoli, Jerusalén, 1948, pp. 143-144, cit. en GUGLIELMI, Guía, p. 203.

29 Itinerario ai Paesi orientali di fra Riccoldo da Monte di Cruce dominicano scritto del XIII secolo dato ora in luce da fra Vincenzo Fineschi sacerdote dello stesso ordine, Florencia, 1783, p. 42. 
Cuando el burgués florentino Leonardo Frescobaldi peregrinó por Tierra Santa entre 1384 y 1385, al prepararse a cruzar el desierto en la península del Sinaí, se le previno de la necesidad de llevar consigo una gran cantidad de bizcocho, y en la relación de su viaje aclaró que esto se debía a que los peregrinos podrían necesitar esos alimentos de más para aplacar a los musulmanes que hallaran por el desierto, «para que no nos trataran mal» ${ }^{30}$.

También, al atravesar el país del Sinaí, el flamenco de familia genovesa Girolamo Adorno, durante su peregrinación a Tierra Santa en 1470-1471, tuvo que enfrentarse al temor a los lugareños, cuando el guía camellero que él y sus compañeros llevaban insistió en desviar la ruta para acudir a visitar a unos amigos suyos en las proximidades, y exigió a los peregrinos occidentales que le proporcionaran algo para llevarles de regalo. Al recordar la aventura, Adorno, sin abandonar su flema habitual, consigna el miedo que todo aquello les causó:

«Fue necesario aceptar, a despecho del temor que teníamos de que nos tendiera emboscadas» ${ }^{31}$.

Otras veces, viajando por mar, era el simple avistamiento de otros barcos el que evocaba el terror de los piratas: el mismo Girolamo Adorno recuerda cierta ocasión en que él y sus compañeros de peregrinación vieron un barco que transportaba musulmanes fuertemente armados; al punto creyeron habérselas con piratas, «lo que nos causó gran temor» ${ }^{32}$, como reconoce paladinamente, sin necesidad de disimular el miedo que entonces sintieron.

En el relato francés anónimo de una peregrinación a Tierra Santa en 1480, se refleja muy bien el miedo al turco como enemigo temible, cuando los viajeros, a bordo de una galera que los conducía a destino, avistaron un barco de guerra turco a la altura de las islas griegas y entonces:

«tous, tant le patron que tous ceulx de la gallée, estions en grant peril et doubte dudict Turc; car si notre Seigneur ne nous eust preservez en nous donnant bon vent, nous estions perduz et cheuz entre les mains des ennemys de Dieu et de la foy chrestienne qui estoyent sur mer et sur terre» ${ }^{33}$.

Por mar y por tierra: por aquellos años finales del siglo XV, la amenaza del turco era muy acuciante y muy real en el Mediterráneo oriental, y también en una ocasión previa, durante el mismo viaje, cuando a bordo de la galera pasaban a lo largo de la costa albanesa, dejando atrás Venecia y Ragusa, los peregrinos fueron

30 Visit to the Holy Places of Egypt, Sinaï, Palestine and Syria in 1384, by Frescobaldi, Gucci and Sigoli (BELLORINI, T., HOADE, E., eds.), Jerusalén, 1948.

31 Itinéraire d'Anselme Adorno en Terre Sainte (1470-1471) (HEERS, J., DE GROEER, G., eds.), París, 1978, p. 225.

${ }^{32}$ Cit. en GUGLIELMI, Guía, pp. 99-100.

${ }^{33}$ Le Voyage de la Saincte Cyté de Hierusalem (SCHEFER, C., ed.), París, 1882, p. 53. 
presa de gran agitación por el avistamiento nocturno de fuegos encendidos en tierra; el temor a un asalto turco sobre la galera los tuvo velando toda la noche:

"Et environ soupper, vismes une gallée saillir devers la ville et cuidions qu'elle vint à nous; et à celle heure, nous faillit le vent et ne pouvoyt aller nostre gallée ne avant ne arriere. Après soleil couchant, avoit sur une grant montaigne dessus ladicte ville plusieurs grans feux que faisoyent lesdictz Turcz; à cause de quoy, nous fusmes bien esbahis et fusmes toute la nuict en grant peur et danger, et firent les pellerins le guet avecques les galiotz toute la nuict, craignant que lesdictz Turcz venissent assaillir nostre gallée» ${ }^{34}$.

El miedo al asalto del turco, o de cualquier pirata, era uno de los temores típicos de quienes se hacían a la mar. En un curioso "cuento dentro del cuento», la narración que en Burgos hicieron al barón de Rosmithal y sus compañeros de la historia legendaria del hallazgo, en alta mar, a bordo de un galeón vacío, de la famosa imagen del Cristo de Burgos, aparece de nuevo el Leitmotiv del miedo de quienes abordaron este galeón a ser víctimas de un asalto de piratas, aunque no se tratara esta vez de turcos ni de infieles:

«creyeron que el galeón era de catalanes (los cuales, aunque son cristianos, se entregan al robo en los mares, y por esto todos concibieron gran miedo); acercáronse algo, si bien con recelo, a la nave y no vieron nada en ella; pero temieron que estuvieran ocultos acechando [...]»35.

\subsection{El miedo al mar}

Junto al temor a ser víctima de una agresión por parte de fieras u hombres, uno de los motivos que con mayor frecuencia aparece asociado a vivencias angustiosas y experiencias-límite en el contexto de las relaciones de viajes en tiempos medievales concierne a los peligros del medio y del entorno: los embates de un clima extremado y de fenómenos atmosféricos como las tormentas, que, especialmente en el mar, constituyen uno de los motivos de miedo más indeleblemente asociado, en la mentalidad y el recuerdo de aquellos hombres, a la experiencia de sus viajes.

Centrándonos en estas últimas, hemos de reconocer la extraordinaria frecuencia con que las travesías por mar (y dentro de éstas, las tormentas) aparecen caracterizadas como motivos de temor en las relaciones de viajes. Para empezar, la sola vista del mar, siempre impresionante, podía llegar a atemorizar a quienes nunca se habían aproximado a la costa; es el caso de los compañeros de viaje de fray Félix Fabri, unos caballeros alemanes jóvenes que hicieron con él la travesía

34 Ibidem, pp. 39-40.

35 GARCÍA MERCADAL, Viajes, t. I, p. 248. 
de los Alpes y cuando desde tierra avistaron el mar quedaron estupefactos y llenos de miedo:

«Vimos el mar Mediterráneo, ante cuya presencia mis señores, jóvenes y delicados, estaban como aterrados y contemplaban los peligros futuros ${ }^{36}$.

Una vez a bordo, no era preciso que el cielo se obscureciera o que amenazase tormenta para que el miedo hiciera acto de presencia entre los pasajeros y aun entre los tripulantes: es más, el paso de algunas travesías que los miembros de la tripulación conocían como especialmente peligrosas invertía en esta ocasión la graduación del miedo, y así los pasajeros, menos versados en las cosas del mar, podían registrar con un matiz de asombro y mayor frialdad el temor de los marineros; así se refleja en cierto momento de la relación de Girolamo Adorno: lia» ${ }^{37}$.

«los marineros experimentaban verdadero horror al pasar por el golfo de Sata-

El mar montuoso y encrespado, muy movido y levantando olas enormes, parecía presagiar la ruina del viaje, y podía llegar a aterrorizar intensamente a los viajeros; en un relato de las grandes navegaciones atlánticas de los portugueses incorporado a la relación del viaje ibérico del barón de Rosmithal, se recoge este detalle de la mar movida como motivo de miedo para los marineros:

«a poco de empezar por segunda vez a navegar, vieron unas olas como montañas que parecía que llegaban a las nubes, con lo cual todos sintieron un terror tan grande como si hubiera llegado el día del juicio»38.

En otras ocasiones, el peligro podía venir envuelto en el blanco sudario de la niebla, o en la obscuridad de la noche, cuando atravesando pasos peligrosos el miedo de embarrancar o encallar podía llegar a ser verdaderamente angustioso para los tripulantes de las embarcaciones; así, en la relación que Ruy González de Clavijo, embajador de Enrique III de Castilla ante Tamerlán, hace de su misión al Oriente, se recoge el lance de una travesía muy difícil por mar, cuando su navío a punto estuvo de quedar atrapado por las rocas en unos estrechos desfiladeros a su paso por entre las islas griegas:

«la dicha carraca pasó tan cerca de la tierra que unos falcones pequeños que criavan en una peña, sonavan. E viéronse en peligro, de manera que el nauchel e algunos mercadores e marineros se desnudaron en jubones [prestos a saltar al agua para salvarse del naufragio]. Cuando fueron alargados, entendieron que Dios les avía fecho merced» ${ }^{39}$.

${ }^{36}$ HASSLER, Evagatorium, t. I, p. 79.

7 HEERS-DE GROEER, Itinéraire d'Anselme Adorno, p. 357.

38 GARCÍA MERCADAL, Viajes, t. I, p. 261.

${ }^{39}$ GONZÁLEZ DE CLAVIJO, R., Embajada a Tamorlán (LÓPEZ ESTRADA, F., ed.), Madrid, 1999, p. 95. 
Cuando llegaba la tormenta, las escenas de pánico a bordo eran realmente fuertes, y dejaban una memoria indeleble en quienes las habían vivido; debido a la casi insoportable intensidad traumática de estas experiencias, los términos en que quedaron consignadas en las relaciones de viaje son insuperablemente expresivos y llenos de inmediatez.

Nompar de Caumont, noble de la Guyena, viajó en 1417 a Compostela, y luego emprendió, ya en 1418, una peregrinación a los lugares de Tierra Santa. Durante la travesía por el Mediterráneo llegó un momento en que el fuerte viento destrozó parte de la embarcación; tras confesarse y encomendarse al Creador, la desorientación de los peregrinos hacía juego con la derrota irregular del navío, que habiendo perdido el velamen y otros aparejos erraba a merced de los elementos, sin posibilidad de enderezar el rumbo:

«íbamos de acá para allá por el mar, como perdidos, con temor e inquietud» ${ }^{40}$.

Cuando la tormenta agitaba las embarcaciones, amenazando llevarlas a pique, el mareo y el terror parecían ir de la mano. Así, por ejemplo, queda reflejado en la relación de la peregrinación a Tierra Santa que hizo en 1480 Santo Brascha, funcionario milanés de los Sforza: cuando el barco en que viajaba quedó envuelto en una fenomenal tormenta a la altura de Corfú, Brascha describe el desolado estado de postración, verdaderamente límite, de sus compañeros:

«los peregrinos yacían todos como muertos con tantos vómitos y tanta ansiedad que ninguno podía socorrer al otro » ${ }^{41}$.

Girolamo Adorno y su padre también se vieron envueltos en una tormenta en el golfo de Venecia:

«Comenzamos a invocar al Señor con voz miserable como si hubiéramos llegado al término de nuestra vida y a orar con fervor, pues ya no esperábamos socorro alguno si no era la gracia de Dios [...]. ¡Qué dolorosos fueron entonces nuestros gritos! Cada uno de nosotros miraba a su vecino con angustia bajando los ojos. Mi padre tomó mi mano como si quisiera decirme: “iHijo! Este es mi deseo: muramos juntos'» ${ }^{42}$.

Cuando después de visitar Constantinopla y Pera, el embajador castellano González de Clavijo y sus compañeros navegaban en dirección a la costa turca, se vieron sorprendidos por una fortísima tormenta, de la que acabarían saliendo con vida, si bien su embarcación quedó completamente inservible; como relata, en el

40 Voyage d'Oultremer en Jhérusalem, par le seigneur de Caumont, l'an 1418, París, 1838, p. 91.

41 Viaggio in Terrasanta di Santo Brascha 1480 (MOMIGLIANO LEPSCHY, A. L., ed.), Milán, 1966, p. 124.

42 HEERS-DE GROEER, Itinéraire d'Anselme Adorno, p. 367. 
fragor de la tormenta la sensación de impotencia y aturdimiento era total, realmente incapacitaba para la acción:

«E la tormenta cresció tanto que era espanto; e todos se encomendavan a Dios, ca pensavan que nunca avían de escapar. E las vagas de la mar fazían tan altas, que quebravan e entravan por el un borne e salían por el otro. E la galeota trabajava mucho e fazía mucho agua. E en poca de hora tal tornó la gente, de que los más d'ellos no fazían de sí cuenta, salvo esperar la merced de Dios».

Debido a este estado de postración de los viajeros, cuando llegó el momento en que el viento cambió y era preciso mover la vela, muy pocos pudieron recolectar sus fuerzas y acudir a ayudar a ejecutar la maniobra:

«E volvieron el antena e, al volver, avía muy pocos que ayudasen, que los más d'ellos estavan más cerca de la muerte que de la vida; e que si la muerte veniera, que la sintieran muy poco» ${ }^{43}$.

Cuando el peligro parecía pasado, y la mar recobraba la calma, el temor padecido con frecuencia había dejado secuelas traumáticas muy profundas, de manera que el retorno a la normalidad del viaje, y el reanudar su narración, se hacían esperar por un tiempo. En muchas relaciones de viajes por mar se recoge elocuentemente este momento ingrato del difícil retorno a la normalidad, cuando gran parte del miedo aún seguía presente y los afectados luchaban por sobreponerse.

Así pinta esta extraña sensación el fraile franciscano Niccolò da Poggibonsi, que entre 1346 y 1350 participó en una peregrinación a Tierra Santa y tuvo ocasión de conocer una de estas violentas e inolvidables tormentas a bordo:

«[Cuando la tormenta había pasado,] uno al otro se miraban como entontecidos. Todos parecíamos salir de la sepultura, a tal punto estábamos desfallecientes y amarillos. Y todo esto, debido al temor ${ }^{44}$.

También el anónimo autor de la peregrinación a Jerusalén editada por Schefer hace una referencia significativa a otro ejemplo de cambio de color en quienes sufrían estos miedos tan grandes durante las travesías por mar: en este caso, fueron los cabellos y las barbas del mismísimo patrón de la nave los que súbitamente encanecieron en una ocasión de grave peligro:

«Le patron nous conta que, une foys, en passant par devant ledict gouffre, il fut en si grant dangier et eut si grant paour que tout soubdainement sa barbe et cheveulx lui devindrent blancs et encoires à present sont tous gris» ${ }^{45}$.

Pedro Tafur era caballero y protagonizó hazañas que pregonaban su valentía durante sus viajes por Europa entre 1435 y $1439^{46}$, pero cuando se hizo a la mar,

43 GONZÁLEZ DE CLAVIJO, Embajada, pp. 152-153.

44 POGGIBONSI, N., Libro d'Oltramare (1346-1350), Jerusalén, 1945, p. 5.

45 SCHEFER, Le Voyage, p. 54.

46 GUGLIELMI, N., «Sobre Pedro Tafur», en Homenaje a Claudio Sánchez-Albornoz en sus 90 años, Buenos Aires, 1986, t. IV, pp. 299-313. 
una tormenta le hizo utilizar, en la relación de sus viajes, una expresión de temor, algo a lo que no estaba acostumbrado, pero que no tiene empacho en reconocer abiertamente:

«E si yo en tierra firme estuviese, segunt el miedo que avía pasado, para siempre nunca tornara a la mar» ${ }^{47}$.

Y es que los terrores y angustias de un mar embravecido espantaban al más pintado y resultaban difíciles de olvidar.

\subsection{El miedo a la enfermedad}

Uno de los miedos naturales del hombre, el miedo al contagio y a la enfermedad, no podía por menos de manifestarse, asimismo, en ocasión de los viajes. Viajando se visitan países diversos, algunos afectados por el azote de la epidemia, y se alterna con mucha gente, en las posadas, en los caminos, de procedencias diversas, produciéndose incluso ocasionales situaciones de hacinamiento (especialmente a bordo de las embarcaciones), redundando todo ello, para viajeros y peregrinos, en un incremento cierto de las probabilidades de contraer enfermedades contagiosas.

Santo Brascha refiere que, durante su viaje a Tierra Santa, uno de los galeotes de la tripulación del navío en que hacían la travesía del Mediterráneo había contraído la peste en Venecia y más tarde murió de ella, a bordo; cuando esto sucedió, su cuerpo fue arrojado al mar en medio de un ambiente de gran recelo, y más tarde, en el mismo viaje, consideraron la posibilidad de hacer la escala habitual en Zara,

«pero nos abstuvimos a causa de la peste que cundía» ${ }^{48}$.

La perspectiva de un viaje por mar acuciado por la amenaza de la peste no dejaba de ser habitual en la época, y la selección de los puertos donde convenía o no hacer escala estaba en muchos casos determinada por la presencia o la ausencia de epidemias, pestilencias, en cada punto en concreto, al tiempo de llegar a ellos. Así, el anónimo autor de la relación de la peregrinación a Tierra Santa de 1480 editada por Schefer precisa que, durante su travesía mediterránea, en alguna ocasión se abstuvieron de desembarcar por miedo a la peste:

«Vendredy septiesme dudict mois nous passasmes par devant l'isle Cerigue en laquelle y a quatre chasteaulx qui sont aux Veniciens, et au soir, par devant la cité de Napole de laquelle les dictz Veniciens sont seigneurs, et par devant le port de Canée ou nous cuydasmes aller pour ce que on doubtoit qu'il y eust pestilence à Candie» ${ }^{4}$.

\footnotetext{
47 Andanças e viajes de Pero Tafur por diversas partes del mundo avidos (1435-1439) (JIMÉNEZ DE LA ESPADA, M., ed.), Madrid, 1874, p. 191.

48 MOMIGLIANO LEPSCHY, Viaggio in Terrasanta, pp. 54-55.

49 SCHEFER, Le Voyage, pp. 48-49.
} 
Durante el mismo viaje, se producen varias muertes a bordo; hay gran precaución en deshacerse higiénicamente de los cuerpos, y se refleja el temor generalizado entre toda la tripulación y el pasaje de que los demás que iban enfermos estuvieran infectados por enfermedades infecciosas, esto es, por pestilencia:

«Ledict jour, environ disner, trespassa en nostre gallée ung des matelotz aagé environ de XXVIII à trente ans et fut cousu et ensepvely tout vestu en une meschante couverture de laine, et mist on dedans II grosses corbeilles de sablon que on print au fons de ladite gallée, affin que ledict sablon fist enfondrer le corps au fons; et puis incontinent, fut gecté en la mer et fut grant ebahissement, et cuydoit on qu'il fut mort d'epidimie, combien que non ${ }^{50}$.

«ll fut le septiesme mort de nostre gallée: et y en avoit environ une douzaine de mallades dont nous estions tous bien esbahis, parquoy chascun craignoit plus que si la malladie eust esté d'aultre qualité» ${ }^{51}$.

Naturalmente, el hacinamiento y el aislamiento temporal del especial hábitat a bordo hace del miedo al contagio una preocupación típica de las travesías marítimas; pero el fantasma invisible de la peste acecha a los peregrinos también en tierra, debido a la confluencia en unos mismos lugares de habitación de viajeros llegados de las más diversas procedencias. Así, Girolamo Adorno relata la angustia que sus compañeros de peregrinación y él sintieron cuando, llegados al monte Sión, se vieron hospedados, por los franciscanos locales, en unas estancias donde previamente a su llegada se habían producido varias muertes por pestilencia entre los huéspedes anteriores:

«casi cuarenta peregrinos — de los cuales cuatro habían sido nuestros compañeros hasta Rama- habían muerto súbitamente. Esto nos hizo temblar de miedo puesto que no podíamos evitar residir en los mismos lugares en que esos peregrinos habían muerto y satisfacer allí todas nuestras necesidades naturales, pero la gracia de Dios vino en nuestro auxilio como en el caso de los demás peligros» ${ }^{52}$.

\subsection{El miedo a la soledad}

Cuando hablamos de miedo a la soledad en el marco de los viajes medievales no hacemos referencia a una sensación más o menos abstracta de desamparo vital, abulia o vacío, sino de la respuesta natural a la amenaza bien real y bien concreta de un peligro cierto: y es que, lejos de los horizontes de su vida cotidiana, desconectado de las redes de solidaridad familiar y social en que en condiciones normales se desenvolvía su vida, el viajero medieval podía correr auténticos ries-

50 SCHEFER, Le Voyage, p. 33.

51 SCHEFER, Le Voyage, p. 109.

52 HEERS-DE GROEER, Itinéraire d'Anselme Adorno, p. 273. 
gos para su vida y su integridad física cuando se apartaba, siquiera por un momento de los grupos y de las rutas acostumbradas. Separarse del grupo de los peregrinos o viajeros para adentrarse en lo desconocido podía representar, en muchas ocasiones, la diferencia crucial entre la vida y la muerte: así lo sabían y lo entendían los viajeros de aquellos tiempos, y por ello, en las relaciones de sus periplos solían recordar y consignar el miedo intenso que habían sentido cuando alguna vez, por error o imprevisión, les sucedió hallarse, o sentirse solos en medio de un país extraño.

Recordamos, sin ir más lejos, la indicación reveladora que fray Félix Fabri dio sobre cierto tramo de su viaje que le cupo hacer cabalgando en solitario ${ }^{53}$. Más tarde, cuando ya en el Oriente se unió a un grupo de peregrinos que habían acordado atravesar por la ruta usual un tramo del desierto egipcio, al curioso y observador dominico le llamó el espíritu de exploración y se apartó por un tiempo del grupo para curiosear un poco más allá de allí por donde eran conducidos; mas hete aquí que, al bajar de una duna - tal vez por el lado equivocado - el pobre fray Félix se halló solo y no supo encontrar la pista de sus compañeros, ni del campamento, que en cualquier caso no debía estar muy lejos. En medio de un áspero desierto completamente desconocido, y sin puntos de referencia, la situación resultaba en verdad amenazadora, y el fraile vivió momentos de terror:

«pero no pude ver nada, ni humo, ni nuestro fuego, y comencé a temblar de angustia, temiendo no encontrar la vía de mis compañeros, a través de ese terreno sin camino, ir de acá para allá, errando, y que las tinieblas me sorprendieran puesto que si esto ocurriera, sería hombre muerto»54.

Algo parecido, y prácticamente en el mismo lugar, le había acontecido a fray Niccolò da Poggibonsi durante su peregrinación a Tierra Santa un siglo antes: atravesando el desierto egipcio con sus compañeros de peregrinación, les ocurrió que el guía que llevaban fue retenido, y hubieron de seguir solos: el miedo era insoslayable en semejante situación, y no afectaba esta vez a un hombre aislado, sino a todo un grupo de peregrinos, desamparados, solos sin su guía:

«Entonces el temor volvió a renovarse y nos encomendamos nuevamente a santa Catalina» 55 .

\subsection{El miedo a lo desconocido}

Como es fácil de entender, este miedo a la soledad al que acabamos de hacer referencia era en buena medida miedo a lo desconocido, o, por expresarlo con ma-

53 Consignada más arriba, vid. nota 20 del presente trabajo.

54 HASSLER, Evagatorium, t. III, p. 421.

55 POGGIBONSI, Libro d'Oltramare, p. 121. 
yor claridad, el miedo a la soledad podría catalogarse como un tipo especial de miedo a lo desconocido, con la diferencia de que el miedo a lo desconocido puede asaltar a un individuo o a un grupo sin estar inmersos en una situación de soledad.

Cuando en el curso de su misión a Mongolia fray Giovanni del Pian del Carpine y sus compañeros franciscanos iban entrando en territorio tártaro, iban con lágrimas en los ojos, como refiere en cierto pasaje de su mencionada Historia Mongolorum:

«ignorando si íbamos hacia la muerte o hacia la vida»56.

Cruel interrogante, que elocuentemente resume cuanto de incierto e ignoto tenía su angustiosa situación, de expectativa, excitación y negros presagios ante la perspectiva de hollar un país desconocido y potencialmente erizado de peligros.

Cuando fray Félix Fabri visitaba Alejandría de Egipto, preguntó en cierta ocasión a un lugareño por cierto artículo que deseaba comprar, y un comerciante se ofreció a acompañarle a buscar aquello que había pedido; aceptando su ofrecimiento, comenzó primeramente a seguirle, pero cuando observó que se alejaban demasiado y que, por el dédalo de las calles de una gran ciudad como aquella se adentraban más y más en lo desconocido, le entró miedo, y se halló en una situación sumamente incómoda y difícil, pues ignorando la lengua del país, no sabía cómo podría hacer saber a su improvisado guía que desistía de su primer propósito, y si hubiera intentado regresar solo junto a sus compañeros peregrinos pensaba que sin remisión se habría extraviado:

"Comencé a preguntarme con temor si este sarraceno no intentaba abusar de mí, le hice signo de que quería volver sobre mis pasos y me alejé de él. El hombre, al ver esto, se mostró turbado y afligido, dirigiéndome un largo discurso en lengua sarracena, de la que yo no comprendía nada, y levantando los ojos al cielo, como si tomara a Dios por testigo de que yo me encontraba seguro con él. Luego me tomó del brazo, tirando de mí, asiéndome de modo que me impedía huir» ${ }^{57}$.

Lo cierto es que esta vez los temores del dominico se revelaron infundados, pues aquel hombre lo condujo sano y salvo hasta el lugar adecuado, y la compra transcurrió sin sobresaltos.

Ciertamente, encontrarse en países lejanos daba que pensar, inducía a frecuentes episodios de deficiente comprensión con los nativos y, en general, la impresión de enfrentarse a lo desconocido era con frecuencia fuente de temor para los viajeros. Parte de este miedo a lo desconocido se relacionaba, claro está, con la apariencia, la lengua y las costumbres de los habitantes de aquellos otros

56 T'SERSTEVENS, Los precursores, p. 166.

57 HASSLER, Evagatorium, t. III, p. 443. 
países, que en muchas ocasiones aparecían, por su diversidad y exotismo, como amenazadoras para los visitantes. Ejemplo de esto lo hallamos en la descripción que el anónimo autor de la peregrinación a Tierra Santa editada por Schefer hace del primer puerto de Oriente en manos de infieles en que desembarcaron; recordando la experiencia, este peregrino no tuvo reparos en reconocer y evocar el miedo que aquella impresión les causó:

«Nous avions grant peur quant nous descendismes à terre de veoir ces merveilleuses gens et si diversement habillez $\ll^{58}$.

Realmente, para sentir la impresión de hallarse entre gentes extrañas, de costumbres y lengua indescifrables y en apariencia amenazadoras, no parecía necesario aventurarse en un arriesgado viaje por mar hasta los confines orientales del Mediterráneo: esta sensación, tal como la refieren numerosos viajeros medievales, podía experimentarse también en ciertas regiones del «extremo Occidente», como en España, entre los nativos de lengua eusquérica; así los describe el clérigo Aimeric Picaud, francés del Poitou, a mediados del siglo XII:

«Los navarros y los vascos son muy semejantes en cuanto a comida, trajes y lengua [...] suelen comer todo el alimento mezclado al mismo tiempo en una cazuela, no con cuchara sino con las manos [...] si los vieras comer, los tomarías por perros o cerdos comiendo. Y si los oyeses hablar, te recordarían el ladrido de los perros»59.

Tal parece que la sonoridad de aquellos dialectos espantó al visitante francés, si de tal modo viene a animalizar las voces de los nativos.

\section{LOS REMEDIOS FRENTE AL MIEDO}

Como hemos recordado e ilustrado en los apartados anteriores, viajar conllevaba riesgos en la Edad Media, y la conciencia del peligro inherente a los viajes inducía el miedo en los viajeros de la época, de formas diversas. Se trataría, ahora, de estudiar la respuesta a esa emoción elemental: ¿de qué medios se servían los viajeros medievales para conjurar, contrarrestar, vencer (si ello era posible) el miedo que a cada paso hallaban en su camino en el curso de sus periplos y peregrinaciones? Por supuesto, todas las precauciones habituales, todos los preparativos para las contingencias y emergencias, pueden entenderse incluidos, en sentido lato, dentro de esta categoría de medios o remedios frente al miedo en los viajes. Pero en lo que sigue, deseamos ilustrar con algunos ejemplos, concretamente, ciertos modos de afrontar el miedo de los viajes que por varias razones estimamos particularmente interesantes.

58 SCHEFER, Le Voyage, p. 60.

59 MORALEJO, Liber Sancti Jacobi, t. I, p. 519. 


\subsection{La devoción}

Y el remedio que en primer lugar atrae y retiene nuestra atención es la oración en sentido amplio, y en general las prácticas devotas (algunas no exentas de un matiz supersticioso) a las que los viajeros medievales acudían en busca de alivio para el miedo. Sin duda, en la mentalidad de la época, la devoción sincera era el primer remedio contra el miedo y contra los peligros.

En parte, ya hemos visto que, con ocasión de peligros especialmente aterradores, como las tormentas en alta mar que amenazaban con hacer zozobrar las embarcaciones, los peregrinos y otros viajeros medievales recurrían frecuentemente a la oración, a las rogativas y a las promesas piadosas. Así, sabemos que cuando el franciscano Poggibonsi y sus compañeros peregrinos se quedaron solos en el desierto egipcio por deserción del guía, el temor creció en ellos y todos se encomendaron a santa Catalina ${ }^{60}$. Cuando, durante la peregrinación de Santo Brascha, la terrible tormenta en Corfú sembró el terror entre los viajeros, el mismo patrón del barco tomó la iniciativa - como hombre experimentado y que sabía qué hacer en esos casos - y realizó la propuesta de que los presentes contrajeran el voto de designar a uno de ellos para ir en seguida a cierto santuario a agradecer a los cielos la merced que entendían haber recibido por conservar la vida:

«el patrono hizo que todos juntos votásemos para constituir un peregrino a Santa María de Casoppo. Y hecha la recolección de dineros, apenas llegamos a tierra fue enviado dicho peregrino ${ }^{61}$.

Curioso destino el de este hombre: habiendo dejado su patria para peregrinar a los santos lugares, se hace ahora cargo de llevar el voto de sus compañeros de peligros en otro nuevo itinerario de peregrinación que lo desvía del primero; y sabemos de otros muchos ejemplos de viajeros a los que la necesidad de cumplir un voto apartaba del primer objetivo que llevaban.

Por lo demás, la iniciativa del patrono de la embarcación es característica de estas situaciones y se refleja en otros textos parecidos: forma parte de su negocio, como transportista profesional, ocuparse de la seguridad de su embarcación y del pasaje, y en la mentalidad de la época la eficacia de las plegarias, rogativas y votos no despertaba otras dudas que las que cupiera albergar sobre la recta intención de los peticionarios ante los ojos de Dios. La relación de estos episodios en los que el mismo patrón del barco, cuando sobreviene una tormenta, recomienda a los pasajeros la eficacia de diversas prácticas devotas, podría multiplicarse sin dificultad. Bástenos acudir al testimonio del embajador castellano González de Clavijo; cuando en el viaje de ida su barco se vio envuelto en una fenomenal tormenta mezclada con los fuegos del Stromboli, el patrón del navío ordenó cantar las letanías:

\footnotetext{
60 Vide supra, nota 55.

61 MOMIGLIANO LEPSCHY, Viaggio in Terrasanta, p. 124.
} 
«E duró la dicha tormenta martes e miércoles fasta en dos oras de la noche; e las dichas bocas, señaladamente la de Strangol e Volcan, con el grand viento lançavan grandes llamas de fuego e fumo con grand roído. E durando la tormenta, fezo el patrón cantar la ledanía e que todos pidiesen merçed a Dios» ${ }^{62}$.

Los hitos y las costumbres de la navegación incluían el encomendarse a la protección de las divinas personas, los santos, los santuarios y otras devociones extendidas entre las gentes de mar. Podría considerarse si era el miedo, o simplemente la precaución o la costumbre, lo que estaba detrás de estas prácticas devotas; por ejemplo, en la relación del viaje a Tierra Santa editado por Scheffer, los marineros del navío que transporta a los peregrinos superan un peligro en su recorrido, y acto seguido, como en una relación causa-efecto, como por una asociación de ideas, hacen sonar trompetas y dan voces de saludo al pasar frente a un santuario situado en tierra: ¿el saludo a la capilla formaba parte del protocolo habitual de estos viajes, o era un reflejo espontáneo del miedo que la tripulación acababa de dejar atrás luego de superar una dificultad de la singladura?:

«Lundy XIle, après vespres, passasmes entre l'isle de Sazere et lesdictz costez d'Esclavonie en ung destroit qui n'a que environ trois milles de large. Et en tournant le grant voille devant qu'on entrast audict destroit, le vent fist prendre ung tour à la gallée et l'envoya près desdictes costes et mismes environ deux heures à retourner à l'entrée du destroit et bien tost après soupper en passant par devant une chappelle de sainct Pierre et sainct Silvestre, les quatre trompettes et tous les matelots firent trois cris en saluant sainct Pierre et luy recommandant la prosperité de la gallée» 63 .

En Venecia, una ciudad que debía la mayor parte de su prosperidad al negocio de la mar, el día de la Asunción, en la ceremonia simbólica de los esponsales anuales de los dogos con el mar, una oración que se rezaba en la iglesia de San Niccolò del Lido encomendaba la seguridad de los navegantes a la protección de la divina providencia:

«Protege, oh Señor, de las tempestades a tus fieles marineros, guárdalos del naufragio improviso y de las pérfidas tramas de enemigos astutos» ${ }^{64}$.

En el conocido relato del misterioso viaje fantástico-alegórico de San Brandán y sus compañeros, cuento de aventuras que no recoge Jacobo de Vorágine en su Leyenda dorada, se hace especial mención de la protección divina que, concedida a los participantes en dicho viaje, les ponía a salvo de todo peligro - y debería también ponerlos a resguardo del miedo:

«Un mensajero les advierte: "Cualquier peligro que veáis, seguid confiados; cualquier cosa que surja, no tengáis miedo: Dios os dará feliz destino, y gracias a

62 GONZÁLEZ DE CLAVIJO, Embajada, p. 91.

63 SCHEFER, Le Voyage, p. 31.

${ }^{64}$ Cit. en GUGLIELMI, Guía, p. 7. 
la bondad divina habéis de ver aquello que vais buscando'. Ahora es cuando se dan cuenta los servidores de Dios que ellos viajan por mandato divino» 65 .

\subsection{El conocimiento}

Vimos antes que entre los motivos o causas del miedo en los viajes ocupaba un lugar destacado la aversión a lo desconocido; parece lógico, en consecuencia, que uno de los medios de afrontar el miedo sea, precisamente, combatir la incertidumbre de los viajes adquiriendo un conocimiento previo de cuanto en ellos podía esperar hallar el viajero. Conocer de antemano la ruta, sus azares y peligros probables, las circunstancias del clima, los alojamientos, la alimentación, los medios de transporte disponibles en cada tramo del recorrido, sin duda podía tranquilizar a los futuros viajeros y contrarrestar los miedos que el viaje pudiera deparar.

Pero, cabe preguntar, ¿eran conscientes quienes escribían sobre sus viajes de la utilidad de su quehacer de cara a ayudar a otros posibles viajeros a afrontar con menos miedo y mayores garantías las dificultades de los mismos? Sin duda, uno de los ingredientes fundamentales de la literatura medieval, en prácticamente todas sus diversas manifestaciones, es su función ejemplar. Avisos, consejos, ejemplos: la literatura medieval está llena de declaraciones de intenciones orientadas en este sentido, y el género de viajes no podía resultar ajeno a dicha motivación: un viajero narra su viaje a otros posibles viajeros, para beneficio de quienes estén considerando emprender una aventura parecida, visitar esos mismos lugares. El Codex Calixtinus y otras obras semejantes, como los itinerarios de época antigua, son auténticas guías de viaje destinadas a ofrecer información útil al peregrino; las relaciones que tantos viajeros hacen de sus travesías advierten, aconsejan, enseñan a otros viajeros.

El anónimo autor de la relación de la peregrinación a Tierra Santa de 1480 editada por Schefer lo reconoce y lo explica abiertamente en el mismo frontispicio de su narración: si se decide a emprender la tarea de dejar por escrito los pormenores del viaje, ello se debe a su intención de ayudar a otros que, como él, deseen realizar la misma peregrinación y así puedan beneficiarse de su experiencia:

«Et pour ce que plus facillement et à moins de crainte, en ose entreprendre les choses desquelles on a quelque certitude ou congnoissance sois ou par experience ou à la relation d'aultruy, et aussi que les choses du tout incongneues semblent impossibles ou au moins plus merveilleuses quelles ne sont, j'ay bien voulu, en satisfaisant de mon petit labeur et pouvoir aux devotz pelerins chrestiens qui desirent accomplir le voyaige de Hierusalem iceulx advertir des lieux, perilz et aultres aventures qui peuvent avenir audict voyage ${ }^{66}$.

65 BENEDEIT, Navigatio Sancti Brendanni Abbatis, 1983, pp. 14-15.

66 SCHEFER, Le Voyage, p. 2. 
«Las cosas completamente desconocidas parecen imposibles o, cuando menos, más maravillosas de lo que son»: aguda observación que resume esta idea del conocimiento como antídoto contra el miedo y que explica la motivación ejemplar y utilitaria de las relaciones de viajes.

\subsection{La protección del poder}

El de las disposiciones emanadas de las distintas instancias de poder público que tienen como fin atajar la inseguridad de los caminos es un tema muy bien conocido. El prestigio de la autoridad, y también el interés de fomentar la riqueza de los intercambios, constituyen dos motivaciones típicas para dispensar esta especial protección a los caminos y a sus usuarios, que mayoritariamente son comerciantes y peregrinos.

Es muy sencillo encontrar y acumular noticias sobre esta protección en la documentación regia de la época. Alfonso X, en 1267, dirigiéndose al concejo de Santiago de Compostela, se refiere a los peligros que acechan en los caminos que rodean dicho centro de peregrinaciones:

«Ben sabedes porque vos me enviastes dizer que andauan muchos ladrones et robadores e malhechores en los caminos arredor de Santiago ${ }^{67}$.

A las Cortes castellanas los procuradores en más de una ocasión llevaron quejas sobre la inseguridad de los caminos, y así se recogen entre sus peticiones:

"que quando los omes buenos van a las ferias e a los mercados, e a los puertos de la mar [...], que los roban e los peyndran por los caminos, et maguer lo muestran a los merinos, que non pueden ende aver derecho»68.

La prevención de los asaltos y la protección de los caminantes es una de las motivaciones que llevan a la constitución de ligas de autodefensa, las llamadas hermandades, como consta por muchos testimonios acerca de su creación:

"Sepades que me dixeron que en toda la mi tierra que se fazian muchos robos e males e dannos, en manera que los omes non osan andar seguros, por lo qual me viene a mi muy grant deseruiçio, e a los que biuen e andan por los mios regnos, grant danno. Et por esto tengo por bien de mandar faser hermandades entre vosotros, porque guardedes cada unos en su comarca que non roben nin fagan mal nin danno alguno.

Porque vos mando, vista esta mi carta o el traslado della signado como dicho es, a cada uno de vos en vuestros lugares, que fagades luego hermandades entre

67 Cit. en FERREIRA, E., «Los caminos medievales de Galicia», Boletín Auriense Anexo 9, Orense, 1988, p. 50.

68 Cortes de León y Castilla, t. I, Madrid, 1881, p. 108 ss.: Cortes de 1293. 
vosotros, en la manera que vieredes que se puede faser mejor, e que fagades muy bien guardar los caminos, que non roben nin fagan mal alguno, por que los que biuen en la mi tierra e los que por ella andudieren, anden saluos e seguros con todo lo suyo $[\ldots]{ }^{69}$.

Sin duda, cuando se trata de considerar los remedios contra el miedo, las actuaciones del poder público en defensa de la seguridad de los caminantes y viajeros deberán ocupar un lugar en la explicación del fenómeno.

\subsection{El entretenimiento}

Y ya, en un orden menor, podría agregarse que, tenido en cuenta todo lo anterior, las diversiones y entretenimientos de los viajeros sin duda les servían como remedio eficaz para liberar, siquiera momentáneamente, la mente de los cuidados y riesgos de su camino y, por un tiempo, distrayéndose, aliviar la carga del miedo asociado a los peligros de su aventura. De esta índole, son, por supuesto, los cuentos que los viajeros se refieren unos a otros para aliviar el tedio y ahuyentar los miedos del camino, siguiendo una costumbre tan ampliamente extendida que ha pasado a constituir uno de los ingredientes típicos de la literatura de viajes: pues los cuentos de Canterbury recogidos por Chaucer, o los del Decameron de Boccaccio, como es bien sabido, no tienen otro origen.

Podemos citar aquí un breve testimonio en el que un viajero de la época relaciona de manera explícita la diversión y los entretenimientos como un remedio al miedo pasado en el recorrido. Se trata, una vez más, de la relación que el expresivo y buen observador dominico fray Félix Fabri dejó escrita de su peregrinación (Evagatorium) a Tierra Santa. Según refiere, cuando él y sus compañeros se alojaron en un establecimiento hospedero en la población de Trento, fueron agasajados por un juglar que, con sus cantos, procuraba distraerlos de sus pasadas preocupaciones, de los riesgos que últimamente habían afrontado durante su viaje. Según el elocuente testimonio del fraile, este juglar actuaba «para aliviar nuestra tristeza y ansiedad ${ }^{70}$.

\section{CONCLUSIONES}

Como hemos visto, el miedo fue en los tiempos medievales un ingrediente inseparable de la experiencia de los viajes, debido a la inseguridad general de las rutas y los caminos, y a los azares y peligros del entorno y de los medios de trans-

69 DÍAZ MARTíN, L. V. (ed.), Colección diplomática de Pedro I de Castilla 1350-1369, t. IV, Salamanca, 1999, doc. no. 1378, pp. 262-263: orden del rey de formar hermandades en los concejos, dada en Toledo, el 26 de mayo de 1367: es el ejemplar enviado a Murcia.

70 HASSLER, Evagatorium, t. I, pp. 76-77. 
porte. La vivencia del miedo alcanza a viajeros de toda condición, tanto a quienes se desplazan por motivos de piedad (romeros, peregrinos) como a los mercaderes y navegantes profesionales; a los magnates y caballeros que viajan con sus comitivas, y a los pobres que se asocian en una precaria pero significativa solidaridad del camino con otros semejantes para compartir los azares, los riesgos y la mutua compañía a lo largo de su viaje.

En las relaciones de viajes, un género en sí mismo dentro del panorama de las literaturas medievales, tanto por lo que se refiere al núcleo de la literatura latina como a las diversas tradiciones en lenguas nacionales, no escasean las referencias a los peligros asociados a los viajes. Algo más infrecuentes que estas referencias a los peligros en los viajes son los pasajes en los que los autores de la época reflejan de manera expresa el miedo sentido ante dichos peligros. Sea por convencionalismos de género o por una expresividad reticente propia de la época, lo cierto es que los autores de aquellas relaciones de viajes, habitualmente elocuentes en representar a sus lectores u oyentes las ocasiones de peligro en que se vieron envueltos, se mostraron más esquivos en reconocer el miedo que éstas les habían inspirado. La «emergencia del yo» narrativo y el triunfo de la subjetividad se asocian al espíritu moderno subyacente a las mutaciones estéticas del llamado Renacimiento de los siglos XIV al XVI: si esta puede ser una clave en la dirección correcta para interpretar la mayor o menor proclividad de los autores a recoger sus reacciones emocionales y expresar sus sentimientos ante los acontecimientos relatados, en esta modesta contribución no habremos hecho sino apuntarla, simplemente.

Pero entre los motivos de miedo y terror presentes en la narrativa de viajes medieval destaca, por derecho propio y con caracteres específicos (como hemos visto), el mar y sus peligros. Podría afirmarse con carácter general que, cuando en una relación de viajes de la época llega el momento de referir una travesía por mar, y no digamos ya cuando durante ésta acaece alguna tempestad, las probabilidades de que el autor de la relación deslice expresiones elocuentes de temor se incrementan de manera muy notable. En nuestro estudio tan sólo hemos pasado revista a un pequeño número de textos representativos, pero estimamos que la impresión resultante podría verse confirmada en términos propiamente estadísticos, utilizando una muestra de mucha mayor escala: y es que, de todos los peligros que en la época se ofrecían a la consideración del viajero, el mar constituye, de lejos, el objeto de temor más acuciante y sugestivo, y el que arranca, de quienes narran estos viajes, las expresiones más claras y vehementes de angustia y miedo.

Sobre los remedios y ayudas psicológicas para contrarrestar los efectos del miedo en los viajes, basta la breve relación de ejemplos consignada más arriba como muestra representativa; aquí, como se corresponde con la mentalidad de la época, la piedad religiosa constituye la fuente más estable y confiable de seguridad, y las prácticas de devoción (ribeteadas en ocasiones con elementos supersticiosos) suministran el auxilio más sólido al que aquellos viajeros acudían en los momentos de tribulación. Según esto, el miedo del marinero como el más intenso 
y característico, y el recurso a la devoción como la ayuda más común, nos conducen a la consideración del tropo del marinero piadoso o de la religiosidad de los hombres de mar, que por sí solo vendría a constituir un tema de estudio digno de atención especial.

En conclusión, el tema del miedo en los viajes, por la riqueza y fuerza significativa de sus manifestaciones, queda abierto como un campo fértil para la investigación de las costumbres sociales y de las mentalidades en la época medieval, desde una óptica metodológica amplia, que en el presente estudio simplemente nos hemos contentado con evocar e ilustrar someramente. 
